\title{
Bone marrow-derived stromal cells are associated with gastric cancer progression
}

\author{
H Kasashima ${ }^{1}$, M Yashiro*,1,2, H Nakamae ${ }^{3}$, G Masuda $^{1}$, H Kinoshita ${ }^{1}$, T Morisaki ${ }^{1}$, T Fukuoka ${ }^{1}$, T Hasegawa ${ }^{1}$, \\ K Sakurai ${ }^{1}$, T Toyokawa $^{1}$, N Kubo ${ }^{1}$, H Tanaka ${ }^{1}$, K Muguruma ${ }^{1}$, M Ohira ${ }^{1}$, T Nakane ${ }^{3}$, M Hino ${ }^{3}$ and K Hirakawa ${ }^{1}$ \\ ${ }^{1}$ Department of Surgical Oncology, Osaka City University Graduate School of Medicine, 1-4-3 Asahi-machi, Abeno-ku, Osaka \\ 545-8585, Japan; ${ }^{2}$ Oncology Institute of Geriatrics and Medical Science, Osaka City University Graduate School of Medicine, \\ Osaka, Japan and ${ }^{3}$ Department of Hematology, Osaka City University Graduate School of Medicine, Osaka, Japan
}

Background: The aim of this study was to clarify the role of bone marrow-derived stromal cells (BM-SCs) expressing CD271 in the development of gastric cancer.

Methods: The effect of human BM-SCs on the proliferation and motility of six gastric cancer cell lines, OCUM-2M, OCUM-2MD3, OCUM-12, KATO-III, NUGC-3, and MKN-74, was examined. CD271 expression levels in BM-SCs were analysed by flow cytometry. We also generated a gastric tumour model by orthotopic inoculation of OCUM-2MLN cells in mice that had received transplantation of bone marrow from the CAG-EGFP mice. The correlation between the clinicopathological features of 279 primary gastric carcinomas and CD271 expression in tumour stroma was examined by immunohistochemistry.

Results: Numerous BM-SCs infiltrated the gastric tumour microenvironment; CD271 expression was found in 25\% of BM-SCs. Conditioned medium from BM-SCs significantly increased the proliferation of gastric cancer cell lines. Furthermore, conditioned medium from gastric cancer cells significantly increased the number of BM-SCs, whereas migration of OCUM-12 and NUGC-3 cells was significantly increased by conditioned medium from BM-SCs. CD271 expression in stromal cells was significantly associated with macroscopic type-4 cancers, diffuse-type tumours, and tumour invasion depth. The overall survival of patients $(n=279)$ with CD271-positive stromal cells was significantly worse compared with that of patients with CD271-negative stromal cells. This is the first report of the significance of BM-SCs in gastric cancer progression.

Conclusions: Bone marrow-derived stromal cells might have an important role in gastric cancer progression, and CD271-positive BM-SCs might be a useful prognostic factor for gastric cancer patients.

Tumour progression is recognised as the product of evolving crosstalk between cancer cells and a variety of stromal components, including fibroblasts, vascular cells, inflammatory cells, and extracellular matrix (Kalluri and Zeisberg, 2006). Of these cells, fibroblasts constitute a major stromal compartment and have a critical role in the progression of carcinoma. Although recent studies on tumour microenvironments report that the interaction between cancer cells and cancer-associated fibroblasts (CAFs) might be important for the progression of some types of carcinomas (Yashiro and Hirakawa, 2010; Fuyuhiro et al, 2012; Tripathi et al, 2012; Harper and Sainson, 2014), the origin of CAFs in tumour stroma is still unknown. Several studies reported that mesenchymal stem cells (MSCs) are recruited into tumour stroma (Karnoub et al, 2007; Bergfeld and DeClerck, 2010; Shinagawa et al, 2010) as well as injured tissue; however, some studies revealed that CAFs originate from various cells (Huang et al, 2014) including normal resident fibroblasts (Mueller et al, 2007), vascular endothelial cells (Zeisberg et al, 2007), or vascular smooth muscle cells and pericytes (Ronnov-Jessen et al, 1995). It has been reported that MSCs in tumour stroma might differentiate into a variety of non-haematopoietic stromal cells including fibroblasts (Suzuki et al, 2011; De Boeck et al, 2013). In particular, bone 
marrow-derived stromal cells (BM-SCs) are the most likely candidate MSCs recruited into the tumour microenvironment (Houghton et al, 2004). Although the significance of CAFs has been reported (Quirici et al, 2002; Das et al, 2013; Rasini et al, 2013; Watson et al, 2013), no report of the importance of BM-SCs in the tumour microenvironment is available.

Some markers, including CD13, CD15, CD73, CD140b, CD144, CD146, CD164, and CD271, have been used to identify MSCs (Buhring et al, 2009; Boxall and Jones, 2012). Among these, CD271, also called neural crest nerve growth factor receptor, is reported as a marker of MSCs (Quirici et al, 2002; Das et al, 2013; Rasini et al, 2013; Watson et al, 2013), especially BM-MSCs (Jones et al, 2008; Noort et al, 2012). In this study, as we are interested in BM-SCs as the origin of myofibroblast, CD271 antibody was used as a marker of BM-SCs. We have previously performed the vimentin and $\alpha$-SMA immunostaining of gastric cancer, and reported that myofibroblasts defined as positive for vimentin and $\alpha$-SMA staining are associated with Borrman type-4 gastric cancer and poor prognosis of patients with gastric carcinoma (Fuyuhiro et al, 2010). Therefore, we examined the correlation between BM-SCs as CD271-positive stromal cells and clinicopathological features in gastric cancer. This is the first report of the significance of BM-SCs in gastric cancer microenvironments.

\section{MATERIALS AND METHODS}

Gastric carcinoma model. Animal experiments were performed in compliance with the guidelines of the Osaka City University Ethical Committee. In vivo experiments were carried out on 4-week-old female athymic BALB/c nude mice (CLEA Japan, Tokyo, Japan). Bone marrow transplants were performed as reported previously (Ishii et al, 2003; Karnoub et al, 2007; Caiado et al, 2013). Nude mice received a whole-body sublethal irradiation $(4 \mathrm{~Gy})$ and then received an intravenous injection of $5 \times 10^{6}$ bone marrow mononuclear cells collected from femurs and tibias of the CAG-EGFP mice (Japan SLC, Hamamatsu, Japan). Mice with bone marrow transplantation were allowed to recover for 2-4 weeks, and orthotopic implantation of gastric cancer cells was performed on the mice as reported previously (Fujihara et al, 1998; Kato et al, 2010). After a small median abdominal incision under sevoflurane anaesthesia, $5 \times 10^{6}$ OCUM-2MLN cells (Fujihara et al, 1998) in a volume of $0.1 \mathrm{ml}$ DMEM were inoculated into the stomach with 30 -gauge needles (Nipro, Tokyo, Japan). These mice were killed 6 weeks after the tumour cell inoculation. After killing the animal, the gastric tumours were removed and frozen in liquid nitrogen, cryosectioned, mounted onto glass slides, or fixed in $4 \%$ paraformaldehyde for paraffin sections and stained with $\mathrm{H} \& \mathrm{E}$. The selected tissue sections were subjected to immunohistochemical staining using antibodies against GFP (1:200; Life Technologies, Carlsbad, CA, USA).

Cell lines. Gastric cancer cell lines, OCUM-2M (Yashiro et al, 1995), OCUM-2MD3 (Yashiro et al, 1996), OCUM-12 (Kato et al, 2010), KATO-III, and NUGC-3 (Nomura et al, 2001), derived from diffuse-type gastric carcinomas, and MKN-74(Motoyama et al, 1986), derived from non-diffuse-type gastric carcinoma, were used. The culture medium consisted of DMEM (Wako, Osaka, Japan) with the addition of $10 \%$ fetal bovine serum (FBS; Nichirei, Tokyo, Japan), $100 \mathrm{IU} \mathrm{ml}^{-1}$ penicillin (Wako), $100 \mathrm{mg} \mathrm{ml}^{-1}$ streptomycin (Wako), and $0.5 \mathrm{~mm}$ sodium pyruvate (Wako). Cells were cultured at $37^{\circ} \mathrm{C}$ in $21 \% \mathrm{O}_{2}$.

Isolation and culture of human BM-SCs. Bone marrow-derived stromal cells were obtained from the iliac crest and plated in a dish with MesenCult-XF Medium (STEMCELL Technologies, Grenoble, France) according to a protocol approved by the Ethics
Committee of Osaka City University Graduate School of Medicine. Adherent layer with every 7 days in fresh medium was cultured until $70-80 \%$ confluence. Bone marrow-derived stromal cells were used between passages 3 and 5 . This study was approved by the Ethics Committee of Osaka City University. Informed consent was obtained from patients before study.

Clinical materials. A total of 279 patients who had undergone a resection of the primary tumour and were confirmed histologically to have sporadic gastric cancer were enrolled in this study. None of the patients had undergone preoperative radiation or chemotherapy. The pathologic diagnoses and classifications were made according to the UICC TNM classification of malignant tumours. The study protocol conformed to the ethical guidelines of the Declaration of Helsinki. This study was approved by the Ethics Committee of Osaka City University. Written informed consent was obtained from all patients.

Flow cytometry analysis. To examine the proportion of CD271positive cells in cultured BM-SCs, the single-cell suspensions were washed in $500 \mu \mathrm{l}$ PBS and resuspended in $100 \mu \mathrm{l}$ per $10^{6}$ cells of PBS. The suspensions were stained with monoclonal CD271-FITC antibody (Miltenyi Biotech, Bergisch Gladbach, Germany) or antimouse IgG H\&L Alexa Fluor 488 (Abcam, Cambridge, MA, USA) at $4{ }^{\circ} \mathrm{C}$ for $10 \mathrm{~min}$. Stained cells were washed two times and resuspended in $500 \mu \mathrm{l}$ PBS. The percentage of positive cells were calculated and compared with isotype-matched control-stained cells. Flow cytometry analysis was performed on a FACScan (BD LSR II; Becton Dickinson, San Diego, CA, USA). Furthermore, to examine the detailed quantification of the proportion of infiltrated bone marrow-derived cells, the orthotopic tumour cell suspensions were stained with anti-CD271 antibody- (Abcam) labelled Alexa Fluor 647 by Alexa Fluor 647 Monoclonal Antibody Labelling Kit (Life Technologies), and anti-F4/80 antibody (FITC) (Abcam) and anti-human/mouse CD11b (PE) antibody (Tonbo Bioscience, Burlingame, CA, USA) at $4{ }^{\circ} \mathrm{C}$ for $10 \mathrm{~min}$.

Preparation of conditioned medium. We prepared conditioned medium (CM) from gastric cancer cell lines and BM-SCs. To obtain CM, the plates with every cell were washed with PBS and then incubated for an additional 3 days in $3 \mathrm{ml} \mathrm{DMEM}$ without FBS. The supernatant was stored as $\mathrm{CM}$ at $-80^{\circ} \mathrm{C}$ until use. As a control, DMEM was used instead of CM.

Proliferation assay. The effect of CM from gastric cancer cells and BM-SCs on the proliferation of each other was determined by Cell Counting Kit-8 (CCK-8; Dojindo, Kumamoto, Japan) assay. A total of $1 \times 10^{3}$ cancer cells or $1 \times 10^{4} \mathrm{BM}$-SCs per well were seeded into two 96-well plates with CM or control. After incubation for $72 \mathrm{~h}$, CCK-8 was added into each well. After incubation at $37^{\circ} \mathrm{C}$, the plate was measured as absorbance at $450 \mathrm{~nm}$ using a microtiter plate reader (PM2004; Wako). The percentage of cell viability was determined as the ratio of the absorbance of the sample vs the control. Three independent experiments were performed.

Wound-healing assay. Gastric cancer cells were cultured in 96-well plates (Essen ImageLock; Essen Instruments, Birmingham, UK). After the cells reached semiconfluence, a wound was created in the cell monolayer with the 96-well WoundMaker (Essen Bioscience, Ann Arbor, MI, USA). Cancer cells were cultured in DMEM with 5\% FBS. Scratched fields were taken pictured every $3 \mathrm{~h}$, and was monitored with Incucyte Live-Cell Imaging System and software (Essen Instruments). The degree of cell migrations were analysed $24 \mathrm{~h}$ after wound treatment as a percentage of wound confluence. The mean of six fields was calculated as the sample value.

Invasion assay. The in vitro invasiveness was measured by twochamber Matrigel invasion assay using the chemotaxicell chambers (Millipore, Billerica, MA, USA) with a $12-\mu \mathrm{m}$ pore membrane filter 
coated with $50 \mu \mathrm{g}$ of the Matrigel (upper chamber) in a 24-well culture plate (lower chamber), as reported previously (Yashiro et al, 1995). Gastric cancer cells $\left(2 \times 10^{4}\right.$ cells per $200 \mu \mathrm{l}$ per chamber) were seeded in the upper chamber, and $500 \mu \mathrm{l}$ of $\mathrm{CM}$ from BM-SCs or DMEM as control with 5\% FBS was added to the lower chamber. After incubation for $24 \mathrm{~h}$, cancer cells that invaded through a filter to the lower surface of the membrane were stained by the Diff-Quik (Sysmex, Kobe, Japan), and were manually counted under a microscope at $\times 200$ magnification. Six randomly chosen fields were counted for each assay. The mean of six fields was calculated as the sample value.

Immunohistochemical determination of CD271. To stain the tissues of gastric cancer patients, anti-CD271 antibody $(1: 40$; Abcam), Ki-67 antibody (MIB-1, ready-to use; Dako, Glostrup, Denmark), and anti-CD31 antibody (1:50; Abcam) were used. To stain the orthotopic tumour of athymic BALB/c nude mice, anti-mouse CD271 antibody (1:150; Abcam), anti- $\alpha$-SMA antibody (1:100; Abcam), anti-F4/80 antibody (1:50; Abcam), and anti-mouse CD11b antibody ( $1: 100$; Tonbo Bioscience) were used. The methods used for the immunohistochemical determination are as per the manufacturer's instructions as reported previously (Kasashima et al, 2014). In this study, CD271 expression of gastric cancer tissues was evaluated by the intensity of staining and the percentage of stained stromal cells at the invading tumour front. It is possible to distinguish the cell types stained, as well as the number of cells and intensity of the immunohistochemical stained, by using the immunohistochemical technique. CD271 expression was evaluated by the intensity of staining and the percentage of stained stromal cells: intensity was given scores $0-2 \quad(0=$ no; 1 = weak to moderate; 2 =intense). The proportion of the CD271-positive cells (\%) was calculated as $100 \times$ number of CD271-positive stromal cells/total stromal cells and given scores $0-4 \quad(0=0 \%, 1=1-19 \%, 2=20-49 \%, 3=50-69 \%$, and $4=70-100 \%)$. The two scores were multiplied to obtain the final result of $0-8$. Expressions were considered positive when scores were 4 or more and negative when scores were 3 or less. Ki-67 expressions were analysed by KI-67 index, the number of MIB-1positive cancer cells in 100 cancer cells. CD31 expressions were analysed by the total length of CD31-positive cells under a microscope at $\times 200$ magnification. Six randomly chosen fields were counted for each patients. The mean of six fields was calculated as the sample value. Evaluation was made by two double-blinded independent observers who were unaware of clinical data and outcome. When a discrepant evaluation between the two independent observers was found, the evaluation was rechecked and discussed.

Immunofluorescence microscopy. To examine the localisation of infiltrated GFP-positive bone marrow-derived cells and F4/80 expression in orthotopic tumour of nude mice, and CD271 expression and $\alpha$-SMA expression in the stroma of gastric cancer, immunofluorescence microscopy was performed. The frozen sections or paraffin-blocked tissues were blocked with 3\% BSA (diluted in PBS) for $30 \mathrm{~min}$ at room temperature. Orthotopic tumour was incubated with anti-F4/80 antibody (1:100; Abcam) for $2 \mathrm{~h}$ at room temperature and secondary antibody incubation (Alexa Fluor 647; 1:200; Abcam) was performed for $2 \mathrm{~h}$ at room temperature. Tissues were further incubated with anti- $\alpha$-SMA antibody (FITC)- (1:150; Abcam) and anti-CD271 antibody(1:100; Abcam) labelled Alexa Fluor 647 by Alexa Fluor 647 Monoclonal Antibody Labelling Kit (Life Technologies) for $2 \mathrm{~h}$ at room temperature and DAPI (Wako; $1: 1000$ ) for $30 \mathrm{~min}$ at room temperature. Tissues were viewed under a fluorescence microscope (Leica Digital Microscopy DMI 6000; Leica Microsystems, Heidelberg, Germany).
Statistical analysis. The $\chi^{2}$ test or Fisher's exact was used to determine the significance of differences between covariates. Survival durations were calculated with the Kaplan-Meier method and analysed by the log-rank test to compare cumulative survival durations among patient groups. In addition, the Cox proportional hazards model was used to compute univariate hazards ratios for the study parameters. In all of the tests, $P<0.05$ was defined as statistically significant. The SPSS software program (SPSS Japan, Tokyo, Japan) was used for the analyses. In vitro, data are expressed as mean \pm s.d. and significant difference was analysed using the unpaired Student's $t$-test.

\section{RESULTS}

BM-SCs infiltrate into the gastric tumour microenvironment. To clarify the contribution of bone marrow-derived cells, we examined the histopathological features of gastric tumours and the effects of inoculation of OCUM-2MLN cells into the gastric wall of nude mice transplanted with bone marrow from the CAG-EGFP mice. Tumours were allowed to grow for 6 weeks, after which the mice were killed and gastric tumours excised. Bone marrow of nude mice after transplantation of GFP bone marrow was used as the positive control of GFP-positive bone marrow-derived cells (Supplementary Figure 1).

Green fluorescent protein-positive bone marrow-derived cells were found in the stroma of gastric tumours. The number of bone marrow-derived cells was much greater in the stroma of gastric tumours compared with that in normal gastric tissue (Figure 1A). Immunofluorescence study was also performed and revealed that some GFP-positive bone marrow-derived cells were existing in the stroma of gastric tumours (Supplementary Figure 2).

CD271 expression in BM-SCs. Flow cytometry was used to confirm that human BM-SCs express CD271. The CD271-positive population represented $\sim 25 \%$ of BM-SCs (Figure 1B). The mean fluorescence intensity of CD271 in BM-SCs (3210) was high compared with that of the isotype control (550). We examined the effect of conditioned media from gastric cancer cells on CD271 expression of BM-SCs by the FACScan analysis. The CM from OCUM-2MD3 did not affect the CD271-positive population of BM-SCs (data not shown).We examined the flow cytometry analysis to quantify the proportion of CD271-negative cell fractions using CD11b antibody and F4/80 antibody. CD11bpositive cells were frequently found in CD271-negative fraction. In contrast, F4/80 expression was correlated with CD271 expression (Figure 1C). About 12\% of tumour cell suspensions were CD271positive cells. To assess the fraction of CD271-negative cells, we used CD11b (a marker of many leukocytes including granulocytes, monocytes, macrophages, and natural killer cells) and F4/80 (a marker of mature macrophages). Although CD11b-positive cells did not have a correlation with CD271-positive cells, F4/80-positive cells had a correlation with CD271-positive cells (Figure 1C). Figure 1D showed that GFP-positive bone marrow derived, F4/80-positive macropharges were existed in the tumour stroma by immunofluorescence stainings. Susequently, as shown in Figure $1 \mathrm{E}$ and $\mathrm{F}$, immunohistochemical analysis using serial section was carried out to compare the localisation of GFP-positive bone marrow-derived cells with that of CD271, $\alpha$-SMA, F4/80, and CD11b-positive cells in the stroma of orthotopic tumour. The serial section showed that a number of GFP-positive cells were found to be positive for CD271, $\alpha$-SMA, and F4/80 but not for CD11b. These findings suggested that CD271-positive bonemarrow derived cells might partially differentiate to $\alpha$-SMApositive myofibroblasts or F4/80-positive macrophages.

Growth interaction between BM-SCs and gastric cancer cells. Conditioned medium from BM-SCs significantly increased the 
A

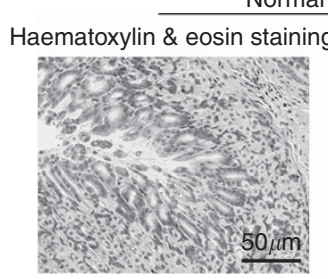

Gastric tumour

Haematoxylin \& eosin staining

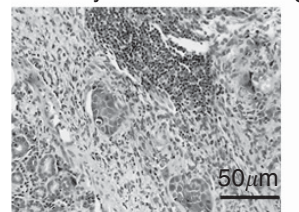

C

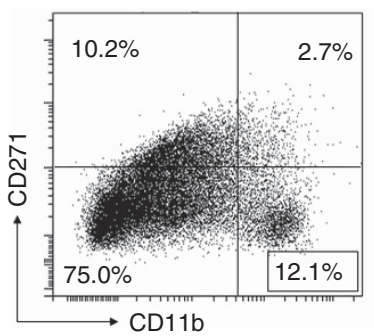

E
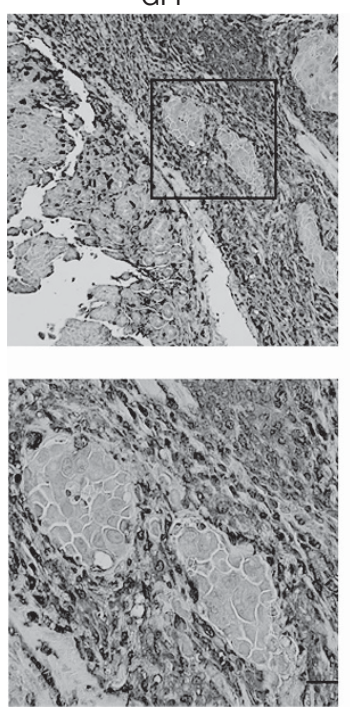

F

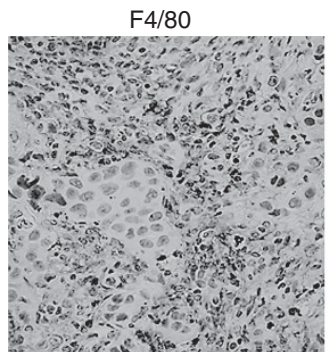

GFP staining
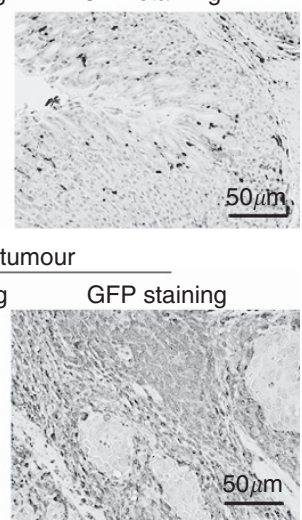

$0 \mu \mathrm{m}$

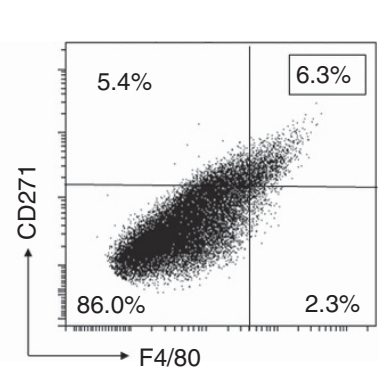

CD271
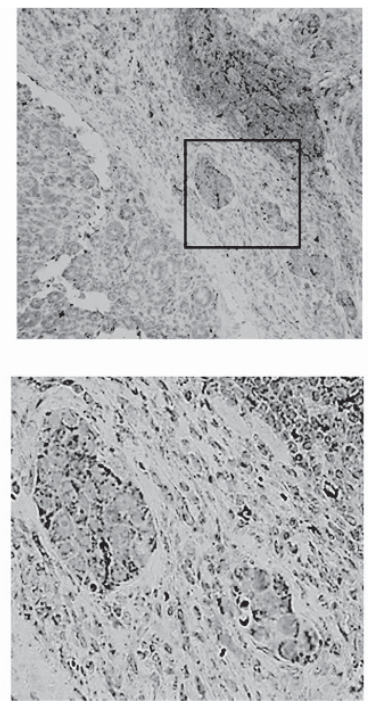

CD11b

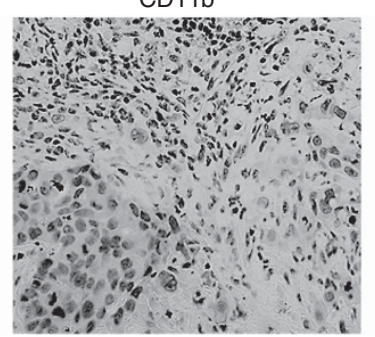

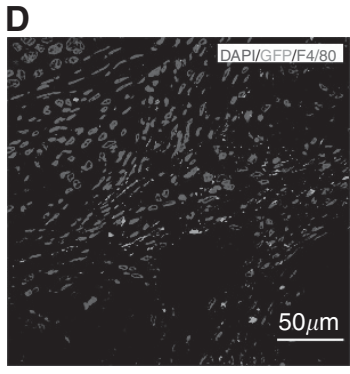

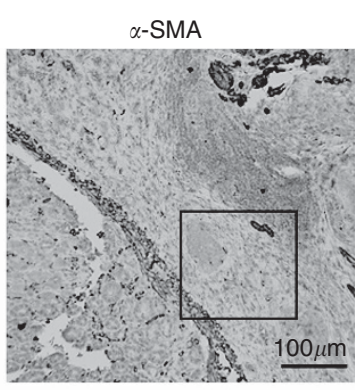

CD271

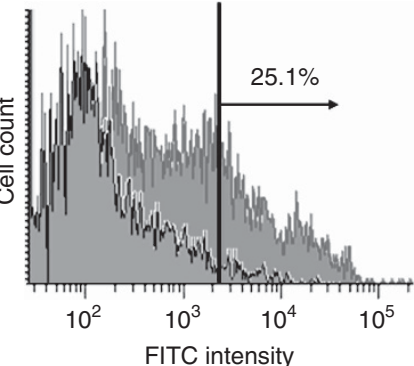

\section{D}

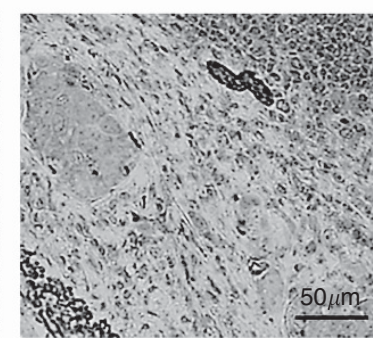

Hematoxylin \& eosin

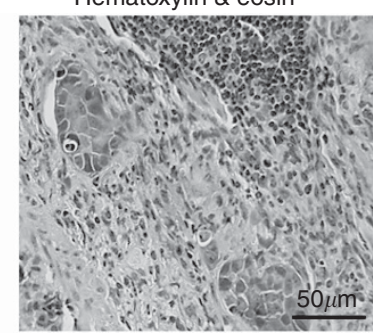

Figure 1. Bone marrow-derived cells. (A) Bone marrow-derived cells infiltrated the stroma of gastric tumours. Green fluorescent protein-positive bone marrow-derived cells were found in far greater numbers in the stroma of gastric tumours compared with that in normal gastric mucosa. (B) CD271 expression in BM-SCs s. Approximately $25 \%$ of BM-MSCs were positive for CD271 expression. (C) Examination of the proportion of infiltrated bone marrow-derived cells in whole tumour suspension. CD271-positive cells were correlated with F4/80-positive cells but not with CD11b-positive cells. (D) Immunofluorescence staining of tumour stroma. GFP and F4/80 double positive cells were found in the tumour. (E and F) Immunohistochemical analysis of the stroma of orthotopic tumour. A number of GFP-positive BM-SCs s were positive for CD271, $\alpha$-SMA, and $\mathrm{F} 4 / 80$ but not for CD11b. A full colour version of this figure is available at the BJC journal online. 


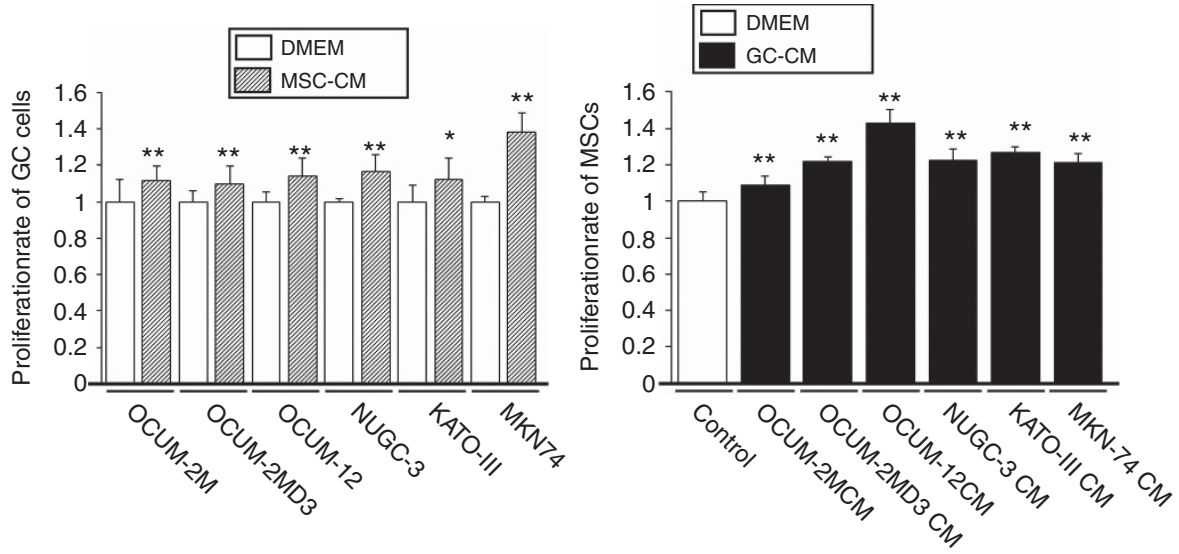

Figure 2. Relationship between BM-SCs and gastric cancer cell proliferation. Conditioned medium (CM) from BM-SCs significantly increased the proliferation of all gastric cancer cell lines compared with the control (Dulbecco's modified Eagle's medium (DMEM)). Conditioned medium from all gastric cancer cell lines significantly increased the number of BM-SCs s compared with the control (DMEM).

proliferation of all gastric cancer cell lines, OCUM-2M, OCUM2MD3, OCUM-12, NUGC-3, KATO-III, and MKN-74 by $11.7 \%$, $9.5 \%, 13.8 \%, 16.3 \%, 11.9 \%$, and $38.3 \%$, respectively, compared with the control. Also, CM from all examined gastric cancer cell lines significantly increased the number of BM-SCs by $8.8 \%, 21.7 \%$, $42.8 \%, 22.3 \%, 27.0 \%$, and $21.5 \%$, respectively, compared with the control (Figure 2).

Effect of BM-SCs on the invasive abilities of gastric cancer cells. Figure 3 shows a representative phase-contrast image of a wound-healing assay performed in this study. Representative images for the calculation of wound confluence are described. Pictures show initial wound mask at $0 \mathrm{~h}$ (yellow) and wound mask at $24 \mathrm{~h}$ (blue). Relative wound confluence (\%) was calculated as $100 \times$ wound closure area at each time-point (blue)/wound area at time 0 (yellow). The number of migrating OCUM-12 and NUGC-3 cells was significantly $(P<0.01)$ increased by the CM from BM-SCs (Figure 3 ). Figure $3 \mathrm{C}$ provides a representative phase-contrast image of OCUM-12 and NUGC-3 cells that invaded into a $12-\mu \mathrm{m}$-pore membrane filter. The number of invading OCUM-12 and NUGC-3 cells was significantly $(P<0.001)$ increased by CM from BM-SCs (Figure 3D).

Relationship between clinicopathological features of gastric cancer and CD271 expression in tumour stroma. CD271positive cells were observed in fibroblasts, vasculature cells, neural cells, and cancer cells, mainly tumour stromal fibroblasts. Human bone marrow was used as the positive controls of CD271 (Supplementary Figure 3). About one-third of cells in human bone marrow was positive for the staining of CD271 antibody. CD271 was expressed on the cell membrane of fibroblasts (Figure 4). The expression of CD271 in vasculature, neuronal, and cancer cells was excluded from this analysis. Table 1 shows the correlation between clinicopathological features and CD271 expression in stromal cells. Among the 279 gastric cancers examined, 159 cases (57\%) were positive for CD271 expression in stromal cells. CD271 expression was significantly correlated with macroscopic type- 4 cancers, diffuse-type tumours, and $\mathrm{T}$ invasion (T3-T4) but not age, gender, lymph node metastasis, lymphatic invasion, venous invasion, hepatic metastasis peritoneal metastasis, or peritoneal cytology.

Immunofluorescence analysis revealed that CD271 expressions in the stroma of gastric cancer were correlated with $\alpha$-SMA expresssions (Supplementary Figure 4). These findings suggested that CD271-positive BM-SCs differentiate into myofibroblasts. In addition, expression levels of Ki-67 in cancer cells of CD271positive patients were significantly higher compared with those of CD271-negative patients (Figure 4D). Furthermore, total length of
CD31-positive cells in the stroma of CD271-positive patients were significantly longer compared with those of CD271-negative patients (Figure 4E).

Overall survival. Figure 4 shows the overall survival of all patients ( $n=279$ ), with CD271-positive stromal cells being correlated with significantly worse prognosis compared with CD271-negative stromal cells $(P=0.025)$. Univariate analysis revealed that the overall survival of patients was significantly correlated with CD271 expression, macroscopic type- 4 cancers, diffuse-type cancers, $\mathrm{T}$ invasion (T2-T4), lymph node metastasis, lymphatic invasion, venous invasion, infiltration, hepatic metastasis, peritoneal metastasis, and peritoneal cytology. Multivariate logistic regression analysis revealed that $\mathrm{T}$ invasion (T2-T4), lymph node metastasis, and peritoneal cytology, but not CD271 expression, were independent predictive parameters for the overall survival of patients (Table 2).

\section{DISCUSSION}

This study showed that GFP-labelled bone marrow-derived cells were abundant in the tumour stroma of gastric cancer in an in vivo model. Houghton et al (2004) also demonstrated that bone marrow-derived cells are recruited to the tumour microenvironment in a mouse model. Flow cytometric analysis revealed that BM-SCs express CD271. These findings suggested that gastric tumour stroma might, in part, consist of CD271-positive BM-SCs. It has been reported that monocyte chemokine protein-1 (Dwyer et al, 2007) and stromal cell-derived factor-1 (Wobus et al, 2015) activate MSC migration to tumour site. These chemokines might be a candidate for the signals to recruit these CD271-positive bone marrow-derived cells.

We next analysed the role of BM-SCs in the development of gastric cancer. Bone marrow-derived stromal cells increased the proliferation and migration of gastric cancer cells, suggesting that BM-SCs might have an important role in the progression of gastric cancer. Terai et al (2014) reported that bone marrow-derived fibrocytes, established from peripheral blood mononuclear cells, were induced to differentiate into myofibroblasts and enhanced the tumour proliferation. In addition, several studies reported that MSCs are associated with the growth of some types of carcinomas (Karnoub et al, 2007; Suzuki et al, 2011; Tsai et al, 2011; De Boeck et al, 2013; Huang et al, 2013). Gastric cancer cells also increased the proliferative activity of BM-SCs in this study. The crosstalk between BM-SCs and gastric cancer cells might be closely associated with the development of gastric cancer. Furthermore, 
A

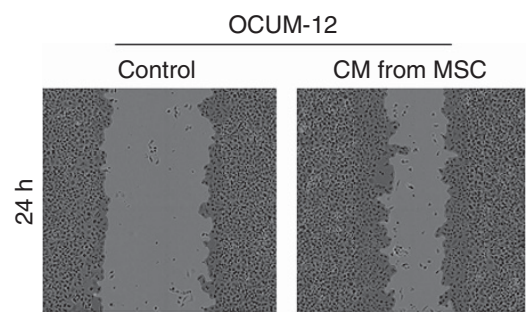

B

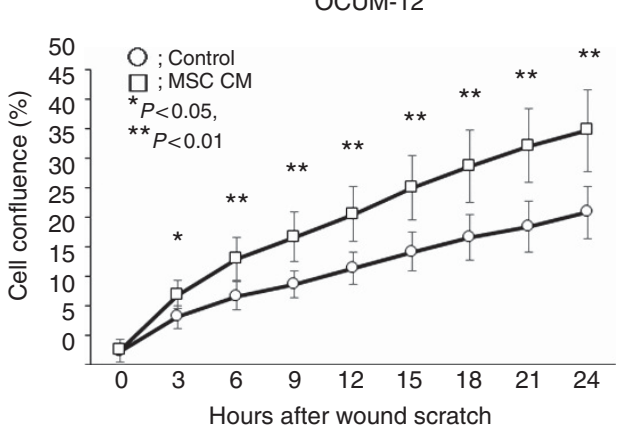

C

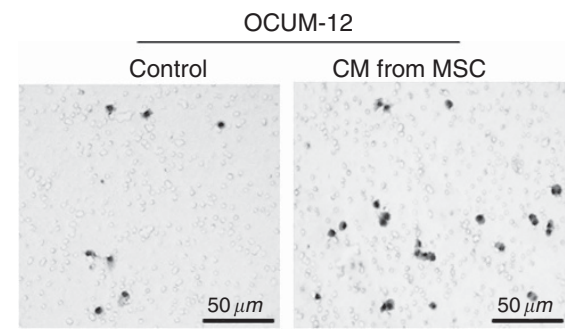

D

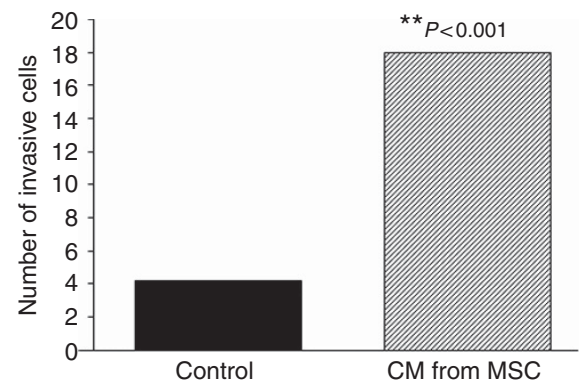

OCUM-12 CM from MSC

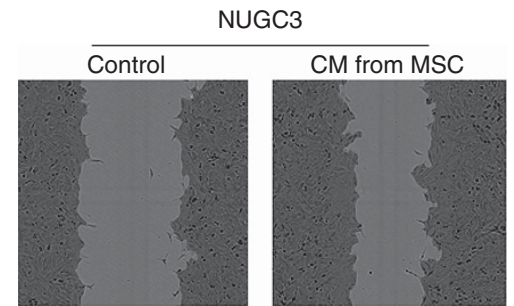

NUGC-3
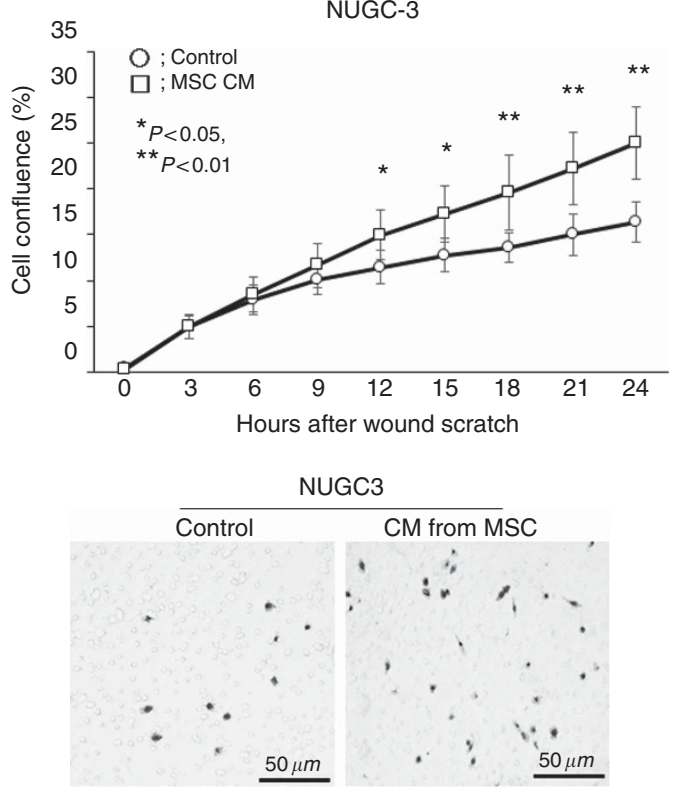

NUGC-3

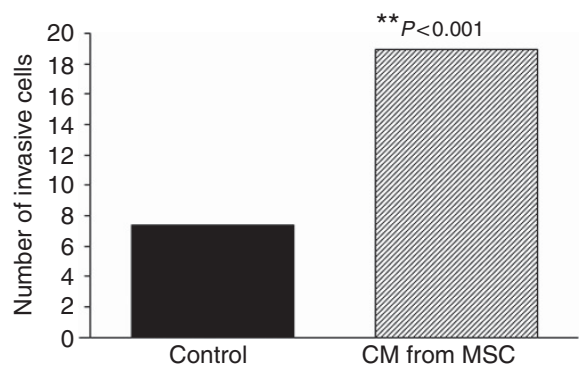

Figure 3. Effect of BM-SCs on the motility of gastric cancer cells. (A) Representative images of cell density in a wound-healing assay. The number of OCUM-12 and NUGC-3 cells migrating across the wound was increased by CM from BM-SCs compared with the control (the absence of CM from BM-SCs). Images show the initial wound mask at $\mathrm{Oh}$ (yellow) and at $24 \mathrm{~h}$ (blue). Relative wound confluence (\%) was calculated as $100 \times$ wound closure area at each time-point (blue)/wound area at time 0 (yellow). (B) Effect of BM-SCs on the migration of cancer cells. Conditioned medium from BM-SCs significantly stimulated migration (round and square line) $(P<0.01)$. (C) Representative images of invading OCUM-12 and NUGC3 cells. The number of cells invading the pore membrane filter was increased by CM from BM-SCs compared with the control. (D) Effect of $\mathrm{BM}-\mathrm{SC}$ s on the invasion of cancer cells. Conditioned medium from BM-SCs significantly stimulated invasion $(P<0.001)$. Data are presented as the mean and s.d. (error bars) of at least four experiments. A full colour version of this figure is available at the BJC journal online.

we examined the effect of BM-SCs on the tumorigenesis of gastric cancer cells in vivo. The tumour size by coinoculation of BM-SCs $\left(5 \times 10^{5}\right.$ cells $)$ and OCUM-2MD3 $\left(5 \times 10^{6}\right.$ cells $)$ were significantly greater compared with that of OCUM-2MD3 $\left(5 \times 10^{6}\right.$ cells $)$ alone (data not shown). Also, it has been reported that BM-derived myofibroblasts become a major component of cancer-induced stromal cells in the later stage of tumour development (Ishii et al, 2003; Quante et al, 2011). Thus, BM-SCs might be a therapeutic target for cancer treatment, as reported previously (Serakinci et al, 2004).

Subsequently, we examined the correlation between CD271positive stromal cells and clinicopathological features of gastric cancer patients by immunohistochemistry. In this study, CD271 expression of gastric cancer tissues was evaluated by the intensity of staining and the percentage of stained stromal cells at the invading tumour front, whereas cancer cells also expressed CD271 as reported previously (Boiko et al, 2010; Imai et al, 2013).

CD271 expression in stromal cells was frequently found in 26 (93\%) of 28 Borrman type-4 gastric cancers that showed diffuse infiltrating carcinoma accompanied by extensive stromal fibroblasts (Japanese Gastric Cancer Association, 2011). We previously reported the close interactions between Borrman type-4 gastric cancer cells and CAFs, especially myofibroblasts (Yashiro and Hirakawa, 2010; Fuyuhiro et al, 2012). In this study, we described the importance of fibroblasts, which migrated from the bone marrow. Also, we reported that gastric cancer cells regulate the characteristics of fibroblasts (Fuyuhiro et al, 2011), which might suggest that gastric cancer cells might regulate BM-SCs s into 
A

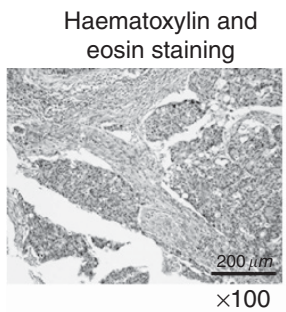

Haematoxylin and eosin staining

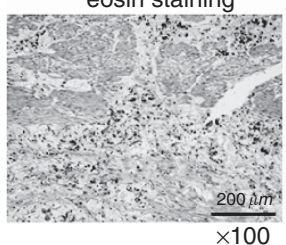

$\times 100$
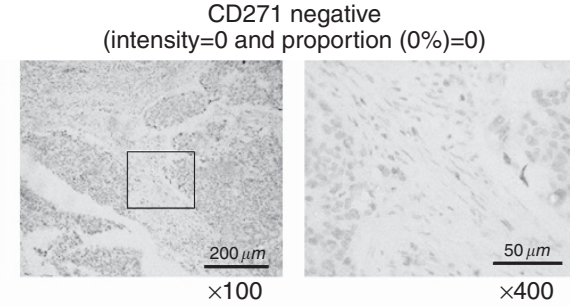

CD271 positive

(intensity=2 and proportion $(90 \%)=4$ )
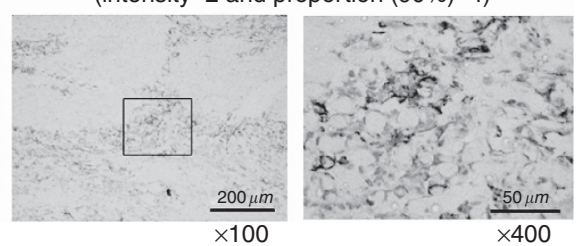

B

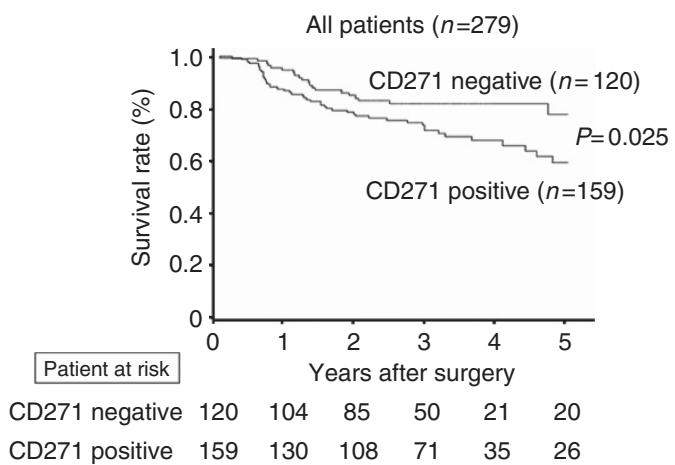

C
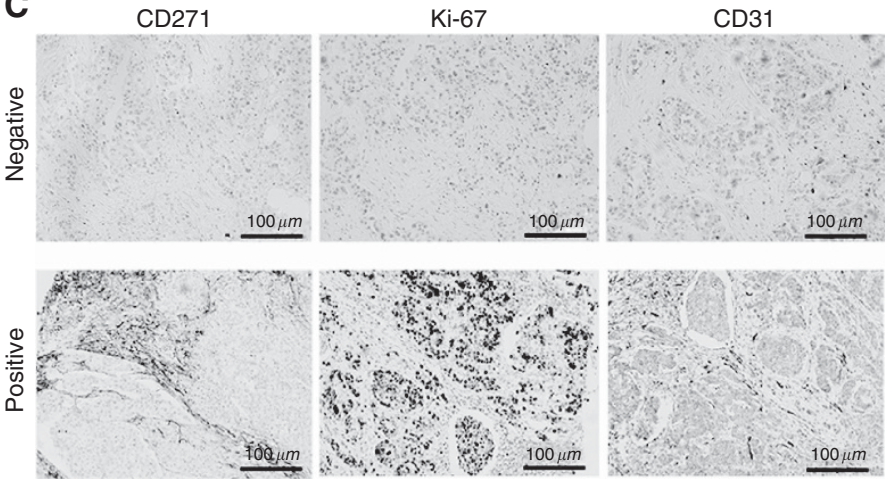

D

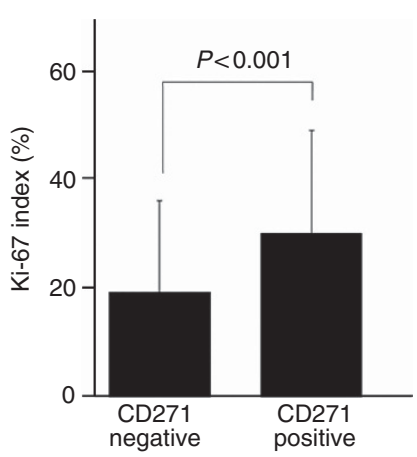

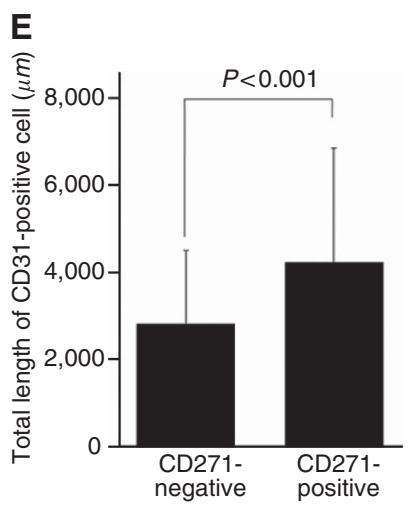

Figure 4. Expression of CD271 and survival of patients with gastric cancer. (A) CD271 was expressed on the membrane of fibroblasts in gastric cancer stroma. (B) Overall survival of all patients $(n=279)$ based on CD271 expression in stromal cells. The Kaplan-Meier survival curve indicates that the overall survival of patients with CD271-positive expression in stromal cells was significantly worse compared with that of patients with CD271-negative expression ( $P=0.025)$. (C) Immunohistochemical analysis of CD271, Ki-67, and CD31. Ki-67 was expressed in the nucleus of cancer cells and CD271 and CD31 was mainly expressed on the membrane of stromal cells. (D) Ki-67 index of CD271-positive patients was significantly higher compared with that of CD271-negative patients $(P<0.001)$. (E) The length of CD31-positive cells in the stroma of CD271positive patients were significantly greater compared with that of CD271-negative patients $(P<0.001)$.

cancer-associated gastric fibroblasts through the interaction between cancer cells and stromal cells in tumour microenvironment. Bone marrow-derived stromal cells in the gastric tumour might change to cancer-associated orthotopic myofibroblasts by the education of gastric cancer cells, and contribute to the tumour progression.

Cancer-associated fibroblasts in type-4 gastric cancer might originate from CD271-positive BM-SCs, and might be closely associated with tumour-stromal interactions in Borrman type- 4 gastric cancer. As described above, it has been suggested that CD271-positive bone marrow-derived cells differentiate to myofibroblasts or macrophages. We previously reported that fibroblast growth factor-7, transforming growth factor- $\beta$, and hepatocyte growth factor from CAFs, which contains myofibroblasts, stimulated the proliferation and invasion ability of gastric cancer cells (Inoue et al, 1997; Nakazawa et al, 2003). These factors from myofibroblasts might be associated with the proliferation and invasiveness of gastric cancer cells. CD271 expression in tumour stroma was positively associated with diffuse-type gastric cancer. It has been reported that CCL5 (Karnoub et al, 2007) and CXCL8 (Ringe et al, 2007) showed chemoattractant activity of BM-SCs. Bone marrow-derived stromal cells might be associated with tumour development of diffuse-type of gastric cancer. These cytokines from diffuse-type gastric cancer might be associated with the accumulation of CD271-positive BM-SCs. Because CD271 expression was frequently found at $\mathrm{T}$ stage 3 and 4, CD271-positive BM-SCs might have an active role at $\mathrm{T}$ stage 3 and 4 . With regard to type after curative surgery in 229 patients, the number of peritoneal metastasis, local recurrence, lymph node recurrence, and hepatic metastasis is $12(5.2 \%), 3(1.3 \%), 21(9.2 \%)$, and $16(7.0 \%)$, respectively. Among these relapse types, the recurrence of peritoneal metastasis was significantly $(P=0.041)$ associated with CD271 expression (Supplementary Table 1).

In this study, Kaplan-Meier survival analysis revealed that CD271-positive patients had significantly (log-rank test, $P<0.025$ ) poorer prognosis compared with CD271-negative patients. In contrast, the multivariate Cox analysis showed that $\mathrm{T}$ invasion was an independent prognostic factor, but CD271 was not. As CD271 expression was correlated with $\mathrm{T}$ stage, CD271 expression might not be an independent prognostic factor.

To determine the tumour proliferative ability and angiogenic index, IHC was performed using anti-MIB-1 antibody and antiCD31 antibody, respectively. Ki-67 index and the tumour proliferative ability of gastric cancer in CD271-positive patients were significantly higher compared with that in CD271-negative patients (Figure 4D). The angiogenic index was analysed by the total length of CD31-positive cells under a microscope at $\times 200$ magnification. Total length of CD31-positive cells in the stroma of CD271-positive patients were significantly longer compared with those of CD271-negative patients (Figure 4E). These findings 
Table 1. Correlation between CD271 expression and clinicopathological features in 279 patients with gastric carcinoma

\begin{tabular}{|c|c|c|c|}
\hline \multicolumn{4}{|c|}{ CD271 expression } \\
\hline $\begin{array}{l}\text { Clinicopathological } \\
\text { features }\end{array}$ & $\begin{array}{l}\text { Positive } \\
(n=159)\end{array}$ & $\begin{array}{l}\text { Negative } \\
(n=120)\end{array}$ & $P$-value \\
\hline \multicolumn{4}{|l|}{ Age (years) } \\
\hline $\begin{array}{l}<60 \\
\geqslant 60\end{array}$ & $\begin{array}{r}49(78 \%) \\
110(52 \%)\end{array}$ & $\begin{array}{l}27(22 \%) \\
93(48 \%)\end{array}$ & 0.136 \\
\hline \multicolumn{4}{|l|}{ Gender } \\
\hline $\begin{array}{l}\text { Female } \\
\text { Male }\end{array}$ & $\begin{array}{r}100(62 \%) \\
59(50 \%)\end{array}$ & $\begin{array}{l}62(38 \%) \\
58(50 \%)\end{array}$ & 0.067 \\
\hline \multicolumn{4}{|l|}{ Macroscopic type } \\
\hline $\begin{array}{l}\text { Other type } \\
\text { Type- } 4\end{array}$ & $\begin{array}{r}133(53 \%) \\
26(93 \%)\end{array}$ & $\begin{array}{c}118(47 \%) \\
2(7 \%)\end{array}$ & $<0.001$ \\
\hline \multicolumn{4}{|l|}{ Histological type } \\
\hline $\begin{array}{l}\text { Intestinal type } \\
\text { Diffuse type }\end{array}$ & $\begin{array}{r}57(46 \%) \\
102(66 \%)\end{array}$ & $\begin{array}{l}68(54 \%) \\
52(34 \%)\end{array}$ & 0.001 \\
\hline \multicolumn{4}{|l|}{$\mathrm{T}$ invasion } \\
\hline $\begin{array}{l}\mathrm{T} 1, \mathrm{~T} 2 \\
\mathrm{~T} 3, \mathrm{~T} 4\end{array}$ & $\begin{array}{l}82(51 \%) \\
77(65 \%)\end{array}$ & $\begin{array}{l}78(49 \%) \\
42(35 \%)\end{array}$ & 0.028 \\
\hline \multicolumn{4}{|c|}{ Lymph node metastasis } \\
\hline $\begin{array}{l}\text { Negative } \\
\text { Positive }\end{array}$ & $\begin{array}{l}85(55 \%) \\
74(59 \%) \\
\end{array}$ & $\begin{array}{l}69(45 \%) \\
51(41 \%) \\
\end{array}$ & 0.544 \\
\hline \multicolumn{4}{|l|}{ Lymphatic invasion } \\
\hline $\begin{array}{l}\text { Negative } \\
\text { Positive }\end{array}$ & $\begin{array}{l}67(57 \%) \\
92(57 \%)\end{array}$ & $\begin{array}{l}51(43 \%) \\
69(43 \%)\end{array}$ & 1.000 \\
\hline \multicolumn{4}{|l|}{ Venous invasion } \\
\hline $\begin{array}{l}\text { Negative } \\
\text { Positive }\end{array}$ & $\begin{array}{r}126(58 \%) \\
33(55 \%)\end{array}$ & $\begin{array}{l}93(42 \%) \\
27(45 \%)\end{array}$ & 0.769 \\
\hline \multicolumn{4}{|l|}{ Infiltration } \\
\hline $\begin{array}{l}a, b \\
c\end{array}$ & $\begin{array}{l}93(49 \%) \\
58(79 \%)\end{array}$ & $\begin{array}{l}97(51 \%) \\
15(21 \%)\end{array}$ & $<0.001$ \\
\hline \multicolumn{4}{|l|}{ Hepatic metastasis } \\
\hline $\begin{array}{l}\text { Negative } \\
\text { Positive }\end{array}$ & $\begin{array}{r}154(57 \%) \\
5(56 \%)\end{array}$ & $\begin{array}{r}116(43 \%) \\
4(44 \%)\end{array}$ & 1.000 \\
\hline \multicolumn{4}{|l|}{ Peritoneal metastasis } \\
\hline $\begin{array}{l}\text { Negative } \\
\text { Positive }\end{array}$ & $\begin{array}{r}146(56 \%) \\
13(76 \%) \\
\end{array}$ & $\begin{array}{r}116(44 \%) \\
4(24 \%) \\
\end{array}$ & 0.129 \\
\hline \multicolumn{4}{|l|}{ Peritoneal cytology } \\
\hline $\begin{array}{l}\text { Negative } \\
\text { Positive }\end{array}$ & $\begin{array}{r}129(56 \%) \\
18(69 \%)\end{array}$ & $\begin{array}{r}101(44 \%) \\
8(31 \%)\end{array}$ & 0.217 \\
\hline
\end{tabular}

suggested that CD271-positive stromal cells might be associated with the proliferative ability of gastric cancer cells and angiogenesis but not invasion. CD271 expression did not correlate with lymph node metastasis, lymphatic invasion, venous invasion, hepatic metastasis, and peritoneal metastasis. In addition, flow cytometric analysis (Figure 1C) showed that CD271-negative cells contain CD11b-positive cells that are designated as immune cells, such as natural killer cells. These immune cells might correlate with better prognosis of 'CD271-negative' gastric cancer cases.

Although CD271 is reported as a marker of MSCs (Quirici et al, 2002; Das et al, 2013; Rasini et al, 2013; Watson et al, 2013), especially BM-MSCs (Jones et al, 2008; Noort et al, 2012), there is no report of the significance of BM-SCs in gastric cancer patients. Thus, this is the first report to describe the significance of BM-SCs in the tumour microenvironment in gastric cancer progression. In future study, it is necessary to detect and quantify circulating CD271-positive cells in the gastric cancer patients to compare their presence with disease progression or clinical remission.
Table 2. Univariate and multivariate Cox multiple regression analysis with respect to overall survival after surgery in 279 patients with gastric carcinoma

\begin{tabular}{|c|c|c|c|c|c|c|}
\hline & \multicolumn{3}{|c|}{ Univariate } & \multicolumn{3}{|c|}{ Multivariate } \\
\hline Parameter & $\begin{array}{c}\text { Hazard } \\
\text { ratio }\end{array}$ & $95 \% \mathrm{Cl}$ & $P$-value & $\begin{array}{c}\text { Hazard } \\
\text { ratio }\end{array}$ & $95 \% \mathrm{Cl}$ & $P$-value \\
\hline \multicolumn{7}{|c|}{ CD271 expression } \\
\hline Positive & 1.818 & $1.079-3.065$ & 0.025 & 1.414 & $0.762-2.622$ & 0.272 \\
\hline \multicolumn{7}{|c|}{ Macroscopic type } \\
\hline Type-4 & 5.866 & $3.496-9.842$ & $<0.001$ & 1.217 & $0.628-0.362$ & 0.561 \\
\hline \multicolumn{7}{|c|}{ Histological type } \\
\hline Diffuse type & 1.988 & $1.204-3.284$ & 0.007 & 1.368 & $0.727-2.573$ & 0.331 \\
\hline \multicolumn{7}{|l|}{$\mathrm{T}$ invasion } \\
\hline T2-T4 & 19.815 & $7.220-54.380$ & $<0.001$ & 6.833 & $1.922-24.290$ & 0.003 \\
\hline \multicolumn{7}{|c|}{ Lymph node metastasis } \\
\hline Positive & 11.152 & $5.701-21.815$ & $<0.001$ & 4.175 & $1.779-9.798$ & 0.001 \\
\hline \multicolumn{7}{|c|}{ Lymphatic invasion } \\
\hline Positive & 8.150 & 3.902-17.019 & $<0.001$ & 0.875 & $0.349-2.196$ & 0.777 \\
\hline \multicolumn{7}{|c|}{ Venous invasion } \\
\hline Positive & 3.811 & $2.373-6.122$ & $<0.001$ & 1.449 & $0.828-2.535$ & 0.194 \\
\hline \multicolumn{7}{|c|}{ Infiltration type c } \\
\hline Positive & 1.836 & $1.132-2.976$ & 0.014 & 0.680 & $0.351-1.316$ & 0.252 \\
\hline \multicolumn{7}{|c|}{ Hepatic metastasis } \\
\hline Positive & 5.906 & $2.679-13.023$ & $<0.001$ & 2.448 & $0.986-6.077$ & 0.054 \\
\hline \multicolumn{7}{|c|}{ Peritoneal metastasis } \\
\hline Positive & 10.593 & $5.725-19.600$ & $<0.001$ & 1.733 & $0.755-3.974$ & 0.194 \\
\hline \multicolumn{7}{|c|}{ Peritoneal cytology } \\
\hline Positive & 11.030 & $6.213-19.580$ & $<0.001$ & 3.544 & $1.653-7.595$ & 0.001 \\
\hline
\end{tabular}

In conclusion, BM-SCs might have an important role in the progression of gastric cancer. CD271-positive BM-SCs might be a useful prognostic factor for patients with gastric cancer.

\section{ACKNOWLEDGEMENTS}

This study is partially founded by KAKENHI (Grant-in-Aid for Scientific Research, Nos. 22390262, 23390329, and 26293307), by the National Cancer Center Research and Development Fund (23A-9), and by Priority Research Fund of Osaka City University.

\section{CONFLICT OF INTEREST}

The authors declare no conflict of interest.

\section{REFERENCES}

Bergfeld SA, DeClerck YA (2010) Bone marrow-derived mesenchymal stem cells and the tumor microenvironment. Cancer Metast Rev 29(2): 249-261.

Boiko AD, Razorenova OV, van de Rijn M, Swetter SM, Johnson DL, Ly DP, Butler PD, Yang GP, Joshua B, Kaplan MJ, Longaker MT, Weissman IL (2010) Human melanoma-initiating cells express neural crest nerve growth factor receptor CD271. Nature 466(7302): 133-137.

Boxall SA, Jones E (2012) Markers for characterization of bone marrow multipotential stromal cells. Stem Cells Int 2012: 975871.

Buhring HJ, Treml S, Cerabona F, de Zwart P, Kanz L, Sobiesiak M (2009) Phenotypic characterization of distinct human bone marrow-derived MSC subsets. Ann NY Acad Sci 1176: 124-134. 
Caiado F, Carvalho T, Rosa I, Remedio L, Costa A, Matos J, Heissig B, Yagita H, Hattori K, da Silva JP, Fidalgo P, Pereira AD, Dias S (2013) Bone marrow-derived CD11b + Jagged 2 cells promote epithelial-tomesenchymal transition and metastasization in colorectal cancer. Cancer Res 73(14): 4233-4246.

Das B, Kashino SS, Pulu I, Kalita D, Swami V, Yeger H, Felsher DW, Campos-Neto A (2013) CD271(+) bone marrow mesenchymal stem cells may provide a niche for dormant Mycobacterium tuberculosis. Sci Transl Med 5(170): 170ra13.

De Boeck A, Pauwels P, Hensen K, Rummens JL, Westbroek W, Hendrix A, Maynard D, Denys H, Lambein K, Braems G, Gespach C, Bracke M, De Wever O (2013) Bone marrow-derived mesenchymal stem cells promote colorectal cancer progression through paracrine neuregulin 1/HER3 signalling. Gut 62(4): 550-560.

Dwyer RM, Potter-Beirne SM, Harrington KA, Lowery AJ, Hennessy E, Murphy JM, Barry FP, O’Brien T, Kerin MJ (2007) Monocyte chemotactic protein-1 secreted by primary breast tumors stimulates migration of mesenchymal stem cells. Clin Cancer Res 13(17): 5020-5027.

Fujihara T, Sawada T, Hirakawa K, Chung YS, Yashiro M, Inoue T, Sowa M (1998) Establishment of lymph node metastatic model for human gastric cancer in nude mice and analysis of factors associated with metastasis. Clin Exp Metastasis 16(4): 389-398.

Fuyuhiro Y, Yashiro M, Noda S, Kashiwagi S, Matsuoka J, Doi Y, Kato Y, Hasegawa T, Sawada T, Hirakawa K (2011) Upregulation of cancerassociated myofibroblasts by TGF-beta from scirrhous gastric carcinoma cells. Br J Cancer 105(7): 996-1001.

Fuyuhiro Y, Yashiro M, Noda S, Kashiwagi S, Matsuoka J, Doi Y, Kato Y, Muguruma K, Sawada T, Hirakawa K (2010) Myofibroblasts are associated with the progression of scirrhous gastric carcinoma. Exp Ther Med 1(4): $547-551$.

Fuyuhiro Y, Yashiro M, Noda S, Matsuoka J, Hasegawa T, Kato Y, Sawada T, Hirakawa K (2012) Cancer-associated orthotopic myofibroblasts stimulates the motility of gastric carcinoma cells. Cancer Sci 103(4): 797-805.

Harper J, Sainson RC (2014) Regulation of the anti-tumour immune response by cancer-associated fibroblasts. Semin Cancer Biol 25: 69-77.

Houghton J, Stoicov C, Nomura S, Rogers AB, Carlson J, Li H, Cai X, Fox JG, Goldenring JR, Wang TC (2004) Gastric cancer originating from bone marrow-derived cells. Science 306(5701): 1568-1571.

Huang L, Xu A, Liu S, Liu W, Li T (2014) Cancer-associated fibroblasts in digestive tumors. World J Gastroenterol 20(47): 17804-17818.

Huang WH, Chang MC, Tsai KS, Hung MC, Chen HL, Hung SC (2013) Mesenchymal stem cells promote growth and angiogenesis of tumors in mice. Oncogene 32(37): 4343-4354.

Imai T, Tamai K, Oizumi S, Oyama K, Yamaguchi K, Sato I, Satoh K, Matsuura K, Saijo S, Sugamura K, Tanaka N (2013) CD271 defines a stem cell-like population in hypopharyngeal cancer. PLoS One 8(4): e62002.

Inoue T, Chung YS, Yashiro M, Nishimura S, Hasuma T, Otani S, Sowa M (1997) Transforming growth factor-beta and hepatocyte growth factor produced by gastric fibroblasts stimulate the invasiveness of scirrhous gastric cancer cells. Jpn J Cancer Res 88(2): 152-159.

Ishii G, Sangai T, Oda T, Aoyagi Y, Hasebe T, Kanomata N, Endoh Y, Okumura C, Okuhara Y, Magae J, Emura M, Ochiya T,

Ochiai A (2003) Bone-marrow-derived myofibroblasts contribute to the cancer-induced stromal reaction. Biochem Biophys Res Commun 309(1): $232-240$.

Japanese Gastric Cancer Association (2011) Japanese classification of gastric carcinoma: 3rd English edition. Gastric Cancer 14(2): $101-112$.

Jones EA, Crawford A, English A, Henshaw K, Mundy J, Corscadden D, Chapman T, Emery P, Hatton P, McGonagle D (2008) Synovial fluid mesenchymal stem cells in health and early osteoarthritis: detection and functional evaluation at the single-cell level. Arthritis Rheum 58(6): 1731-1740.

Kalluri R, Zeisberg M (2006) Fibroblasts in cancer. Nat Rev Cancer 6(5): 392-401.

Karnoub AE, Dash AB, Vo AP, Sullivan A, Brooks MW, Bell GW, Richardson AL, Polyak K, Tubo R, Weinberg RA (2007) Mesenchymal stem cells within tumour stroma promote breast cancer metastasis. Nature 449(7162): 557-563.

Kasashima H, Yashiro M, Kinoshita H, Fukuoka T, Morisaki T, Masuda G, Sakurai K, Kubo N, Ohira M, Hirakawa K (2014) Lysyl oxidase-like 2
(LOXL2) from stromal fibroblasts stimulates the progression of gastric cancer. Cancer Lett 354(2): 438-446.

Kato Y, Yashiro M, Noda S, Tendo M, Kashiwagi S, Doi Y, Nishii T, Matsuoka J, Fuyuhiro Y, Shinto O, Sawada T, Ohira M, Hirakawa K (2010) Establishment and characterization of a new hypoxia-resistant cancer cell line, OCUM-12/Hypo, derived from a scirrhous gastric carcinoma. Br J Cancer 102(5): 898-907.

Motoyama T, Hojo H, Watanabe H (1986) Comparison of seven cell lines derived from human gastric carcinomas. Acta Pathol Jpn 36(1): 65-83.

Mueller L, Goumas FA, Affeldt M, Sandtner S, Gehling UM, Brilloff S, Walter J, Karnatz N, Lamszus K, Rogiers X, Broering DC (2007) Stromal fibroblasts in colorectal liver metastases originate from resident fibroblasts and generate an inflammatory microenvironment. Am J Pathol 171(5): 1608-1618.

Nakazawa K, Yashiro M, Hirakawa K (2003) Keratinocyte growth factor produced by gastric fibroblasts specifically stimulates proliferation of cancer cells from scirrhous gastric carcinoma. Cancer Res 63(24): 8848-8852.

Nomura H, Nishimori H, Yasoshima T, Hata F, Sogahata K, Tanaka H, Nakajima F, Ikeda S, Kamiguchi K, Isomura H, Sato N, Denno R, Hirata K (2001) A novel experimental mouse model of peritoneal dissemination of human gastric cancer cells: analysis of the mechanism of peritoneal dissemination using cDNA macroarrays. Jpn J Cancer Res 92(7): 748-754.

Noort WA, Oerlemans MI, Rozemuller H, Feyen D, Jaksani S, Stecher D, Naaijkens B, Martens AC, Buhring HJ, Doevendans PA, Sluijter JP (2012) Human versus porcine mesenchymal stromal cells: phenotype, differentiation potential, immunomodulation and cardiac improvement after transplantation. J Cell Mol Med 16(8): $1827-1839$

Quante M, Tu SP, Tomita H, Gonda T, Wang SS, Takashi S, Baik GH, Shibata W, Diprete B, Betz KS, Friedman R, Varro A, Tycko B, Wang TC (2011) Bone marrow-derived myofibroblasts contribute to the mesenchymal stem cell niche and promote tumor growth. Cancer Cell 19(2): 257-272.

Quirici N, Soligo D, Bossolasco P, Servida F, Lumini C, Deliliers GL (2002) Isolation of bone marrow mesenchymal stem cells by anti-nerve growth factor receptor antibodies. Exp Hematol 30(7): 783-791.

Rasini V, Dominici M, Kluba T, Siegel G, Lusenti G, Northoff H, Horwitz EM, Schafer R (2013) Mesenchymal stromal/stem cells markers in the human bone marrow. Cytotherapy 15(3): 292-306.

Ringe J, Strassburg S, Neumann K, Endres M, Notter M, Burmester GR, Kaps C, Sittinger M (2007) Towards in situ tissue repair: human mesenchymal stem cells express chemokine receptors CXCR1, CXCR2 and CCR2, and migrate upon stimulation with CXCL8 but not CCL2. J Cell Biochem 101(1): 135-146.

Ronnov-Jessen L, Petersen OW, Koteliansky VE, Bissell MJ (1995) The origin of the myofibroblasts in breast cancer. Recapitulation of tumor environment in culture unravels diversity and implicates converted fibroblasts and recruited smooth muscle cells. J Clin Invest 95(2): 859-873.

Serakinci N, Guldberg P, Burns JS, Abdallah B, Schrodder H, Jensen T, Kassem M (2004) Adult human mesenchymal stem cell as a target for neoplastic transformation. Oncogene 23(29): 5095-5098.

Shinagawa K, Kitadai Y, Tanaka M, Sumida T, Kodama M, Higashi Y, Tanaka S, Yasui W, Chayama K (2010) Mesenchymal stem cells enhance growth and metastasis of colon cancer. Int J Cancer 127(10): 2323-2333.

Suzuki K, Sun R, Origuchi M, Kanehira M, Takahata T, Itoh J, Umezawa A, Kijima H, Fukuda S, Saijo Y (2011) Mesenchymal stromal cells promote tumor growth through the enhancement of neovascularization. Mol Med 17(7-8): 579-587.

Terai S, Fushida S, Tsukada T, Kinoshita J, Oyama K, Okamoto K, Makino I, Tajima H, Ninomiya I, Fujimura T, Harada S, Ohta T (2014) Bone marrow derived 'fibrocytes' contribute to tumor proliferation and fibrosis in gastric cancer. Gastric Cancer 18(2): 306-313.

Tripathi M, Billet S, Bhowmick NA (2012) Understanding the role of stromal fibroblasts in cancer progression. Cell Adhes Migr 6(3): 231-235.

Tsai KS, Yang SH, Lei YP, Tsai CC, Chen HW, Hsu CY, Chen LL, Wang HW, Miller SA, Chiou SH, Hung MC, Hung SC (2011) Mesenchymal stem cells 
promote formation of colorectal tumors in mice. Gastroenterology 141(3): 1046-1056.

Watson JT, Foo T, Wu J, Moed BR, Thorpe M, Schon L, Zhang Z (2013) $\mathrm{CD} 271$ as a marker for mesenchymal stem cells in bone marrow versus umbilical cord blood. Cells Tissues Organs 197(6): 496-504.

Wobus M, List C, Dittrich T, Dhawan A, Duryagina R, Arabanian LS, Kast K, Wimberger P, Stiehler M, Hofbauer LC, Jakob F, Ehninger G, Anastassiadis K, Bornhauser M (2015) Breast carcinoma cells modulate the chemoattractive activity of human bone marrow-derived mesenchymal stromal cells by interfering with CXCL12. Int J Cancer 136(1): $44-54$.

Yashiro M, Chung YS, Nishimura S, Inoue T, Sowa M (1995) Establishment of two new scirrhous gastric cancer cell lines: analysis of factors associated with disseminated metastasis. Br J Cancer 72(5): 1200-1210.
Yashiro M, Chung YS, Nishimura S, Inoue T, Sowa M (1996) Peritoneal metastatic model for human scirrhous gastric carcinoma in nude mice. Clin Exp Metastasis 14(1): 43-54.

Yashiro M, Hirakawa K (2010) Cancer-stromal interactions in scirrhous gastric carcinoma. Cancer Microenviron 3(1): 127-135.

Zeisberg EM, Potenta S, Xie L, Zeisberg M, Kalluri R (2007) Discovery of endothelial to mesenchymal transition as a source for carcinomaassociated fibroblasts. Cancer Res 67(21): 10123-10128.

This work is published under the standard license to publish agreement. After 12 months the work will become freely available and the license terms will switch to a Creative Commons AttributionNonCommercial-Share Alike 4.0 Unported License

Supplementary Information accompanies this paper on British Journal of Cancer website (http://www.nature.com/bjc) 